\title{
Educators' Preferences for Professional Learning Formats by Learning Objective
}

\author{
Cheyne A. LeVesseur ${ }^{1}$, Julie Q. Morrison ${ }^{2}$, Melissa Nantais ${ }^{1}$ \\ ${ }^{1}$ Michigan Multi-Tiered System of Supports (MiMTSS) Technical Assistance Center, USA \\ ${ }^{2}$ School Psychology Program, CECH School of Human Services, University of Cincinnati, USA \\ Correspondence: Julie Q. Morrison, School Psychology Program, CECH School of Human Services, University of \\ Cincinnati, USA.
}

Received: February 4, 2022

doi:10.11114/jets.v10i3.5495
Accepted: March 4, $2022 \quad$ Online Published: March 5, 2022

URL: https://doi.org/10.11114/jets.v10i3.5495

\begin{abstract}
Innovations in information technology have generated an array of options for the professional learning for educators. Face-to-face, remote, and hybrid formats for professional learning each have their advantages and disadvantages for advancing educators' knowledge and skills in evidence-based practices to promote student achievement. The purpose of this study was to better understand teacher and educational leaders' preferences for professional learning formats in relation to the intended learning objective. The results indicate that educators preferences for professional learning format varied by the intended learning objective of the session. Remote professional learning was preferred relative to face-to-face and hybrid formats for a session in which the primary objective was to share information uni-directionally from the presenter to the audience (53\% versus $25 \%$ and $22 \%$ preferred hybrid). The respondents were equally split in their preference for either a face-to-face or remote format when the learning objective was to understand new concepts and learn how to apply the concepts to their setting. The results have important implications for designing professional learning.
\end{abstract}

Keywords: professional learning for educators, remote learning, face-to-face learning

\section{Introduction}

Professional learning for teachers and educational leaders has advanced over the years with the advent of the Standards for Professional Learning (Learning Forward, 2012) coupled with innovations in information technology. Dissatisfaction with the "one-shot workshop" or the two-day "sit and get" has created new opportunities to build the knowledge and skills of educators in keeping with developments in the field. Professional learning initiatives are most effective when they provide opportunities for teachers and educational leaders to interact with each other, receive feedback from their colleagues on their developing practices, and determine how the practice will be implemented in their school (Sun et al., 2017; Sun et al., 2013).

Trends towards the use of technology for efficient, flexible, and cost-effective professional learning received a dramatic boost beginning in March 2020 when the public health crisis, caused by the novel coronavirus (COVID-19) pandemic, required all professional learning to pivot to a remote format. The COVID-19 pandemic created unprecedented challenges and opportunities for training in education and other human services professions (Bell et al., 2020; Besser et al., 2020; Dias et al., 2020). Although the abrupt transition to distance learning was unsettling and disruptive, new approaches to professional learning born out of necessity may permanently alter the way professional learning is designed and delivered (Fichten et al., 2021; WestEd, 2021).

\subsection{Face-to-Face and Online Learning Formats}

Advances in information technology have created opportunities for innovation in how learning transpires (Ituma, 2011). Research conducted with adult learners enrolled in university and community college classes provides insights into preferences for learning formats. Remote, online learning has the perceived benefits of encouraging wider student participation (particularly for students who are typically reluctant to contribute verbally in class), increasing engagement with the course content, and promoting self-directed learning (Alexander, 2001; Chen et al., 2010). With online learning, the learner may be granted more time to think deeply and critically about the course content 
(e.g., Robinson \& Hullinger, 2008). Online learning is also more cost-effective for the institution and the learner (Alexander, 2001). However, learners in online courses report feeling more disconnected from their peers and instructors, more obliged to be self-directed in their knowledge acquisition, and less supported by the instructor (Dvoř́ková et al., 2021; Otter et al., 2013). The expectations for technology access and aptitude can also present challenges for some individuals (Zhang \& Perris, 2004).

As a counterpoint, students who express a preference for face-to-face learning report that they feel more engaged and receive more immediate feedback than they do when learning online (Kemp \& Grieve, 2014). The benefit of being able to rely on an instructor to facilitate their learning is viewed as an advantage of face-to-face learning, in contrast to the expectation for self-directed learning online (Upton, 2006). According to a study of preferences among community-college students, most students preferred to take only "easy" academic subjects online, while they preferred to take "difficult" or "important" subjects face-to-face (Jaggars, 2014). Research shows that preference for format may vary based on the learning activity with face-to-face learning preferred for discussions and online learning preferred for tasks, such as writing, that involve more individual reflection (Kemp \& Grieve, 2014). Furthermore, learners report direct in-person contact is essential for building a sense of community (Conole et al., 2008).

\subsection{Professional Learning Formats for Educators}

Educators seeking to advance their knowledge and skills have traditionally attended conferences, workshops, seminars, or other face-to-face offering. A face-to-face professional learning involves learning that takes place in a common space with both the presenter and the participants. The advantages of face-to-face professional learning include greater opportunities for collaboration and networking, effective communication through access to body language and subtle communication cues, reduced temptation to multi-task, and opportunities to relay more complex information. The disadvantages of face-to-face professional learning for educators include the loss of instructional time for students as teachers are out of the building, travel expenses, the costs of securing substitute teachers.

In contrast, remote professional learning for educators involves learning that takes place via a video conferencing platform where the instructor and the participants are connecting from separate locations. The advantages of remote learning are the efficient, cost effective delivery of content using interactive, multi-media platforms, and the flexibility of being able to attend sessions selectively while being available to address issues at work. The disadvantages of a remote format includes distractions from work/home life, technology challenges (e.g., connectivity, power outages, need for technical support and training), and the inability to freely interact with participants that could lead to valuable exchanges of information and resources.

A hybrid format for professional learning involves learning that takes place with participants and the presenter in a common space with additional participants connecting to that location remotely. A hybrid format offers the advantages of flexibility, convenience, and greater reach by including participants in attendance as well as participants joining virtually. The primary disadvantage of hybrid learning is that the opportunity for collaboration and networking are not shared by all and participants joining virtually may have a difficult time sustaining their focus, reducing distractions and the resisting the temptation to multi-task.

\subsection{Preferences for Professional Learning Format}

Much of what is known about professionals' experiences and preferences for professional learning formats since the start of the COVID-19 pandemic in March 2020 has come from the field of marketing, which relies on in-person conferences as a means of promoting vendor's services and products. PromoLeaf, a purveyor of promotional products, commissioned a national survey of conference participants across a wide variety of industries regarding their preferences for in-person versus virtual conferences. The survey, conducted for PromoLeaf by Censuswide on April 9, 2020 included 1,008 respondents in the United States who had previously attended both an in-person conference and a virtual conference. A majority (72\%) of the participants expressed a preference for an in-person conference, $23 \%$ stated a preference for a virtual conference, and 5\% reported that would prefer neither (PromoLeaf, 2020). Among survey participants aged 16-24, 85\% of the respondents preferred in-person conferences, exceeding the preference for in-person conferences among those aged 25-34 (70\%), 35-44 (67\%), 45-54 (73\%), and 55+ (73\%). Nearly half (46\%) of all of the respondents expressed a preference for conferences that featured a two-way exchange with a question and answer session at the end. An in-person session with the opportunity to access a recording at a later date was viewed positively by nearly $40 \%$. Wednesday was selected as the preferred day of the work week to attend a virtual conference by $34 \%$ of the respondents, followed by Tuesday (25\%). Morning was identified as the preferred time of day to attend a virtual conference across all age groups, with an upward trend favoring mornings across the age group progression.

The results of the PromoLeaf survey yielded slightly more favorable preferences for in-person events that were the results of a survey of business-to-business marketers conducted by Markletic in February 2021. Among a sample of 3,167 respondents from North America (56\% of the sample), Europe (25\%), Asia (10\%), and South America (9\%), 57\% of the 
respondents stated they would prefer to attend an in-person version of a hybrid even rather than the virtual version. Virtual events were preferred by $33 \%$ of the respondents, while $10 \%$ stated they had no preference (Markletic, 2021). Taken together, survey data from the field of marketing indicate that most respondents are favorably inclined towards an in-person format. Virtual events, however, drew more sharply contrasting perceptions with some professionals asserting a strong preference while others expressing their strong dislike.

Specific to the field of education, EdWeek Research Center (2021) conducted a nationally-representative survey of school and district leaders regarding their access, needs, and preferences for their own professional learning. Survey data were gathered from 450 educational leaders from 8/25/2021 to 9/8/2021, during which time school districts were experiencing the COVID-19 pandemic. The majority of respondents selected a preference for in-person professional development training, in sessions that included participants from multiple districts, across categories on the rural/urban continuum: Rural/town regions (selected by $59 \%$ of the respondents), suburban (46\%), and urban (27\%). The second most frequently selected preference was for on-line professional development training delivered on-demand/on my own schedule, as selected by respondents from rural/town (16\%), suburban (16\%), and urban (27\%) regions. There was little distinction in the preference for either: (a) in-person professional development training in sessions limited to colleagues from my district, versus (b) online, live/synchronous training in sessions that include participants from multiple districts. The format preferred by the fewest number of respondents was online, live/synchronous training in sessions limited to colleagues from my district, as selected by respondents from rural/town (4\%), suburban (10\%), and urban (17\%) regions. A similar survey of teachers regarding their preferences for professional learning format is absence from the research gathered since the start of the COVID-19 pandemic.

\subsection{Matching Professional Learning Format to the Learning Objectives}

Rather than seeking to identify a single preferred format for use across all training session for teachers and educational leaders, the design of a professional learning series should follow a plan that is driven by the learning objectives. Learning objectives are statements of expected knowledge or skill mastery that guide the teaching and learning process, assessment, and curriculum development (Schoepp, 2017). Research suggests that learning objectives serve a dual purpose of (a) providing structure for the planning of instruction and (b) communicating to the learner how to prepare for the assessment of learning (Barnard et al., 2020).

The Instructional Hierarchy model (Haring \& Eaton, 1978) has value in determining appropriate learning objectives when the goal of the series is to adopt and master a new professional practice. The Instructional Hierarchy model outlines the stages that an individual progresses through when learning a new skill or practice. The four stages include: (a) acquisition, (b) fluency, (c) generalization, and (d) adaptation. Skill acquisition and fluency reflect the foundational knowledge and practices of teacher or educational leader targeted by a professional learning initiative. Generalization involves the skill proficiency needed to use the foundational practices in a variety of school settings and circumstances. This might include the ability for the teacher or principal to problem solve "on the fly" to apply the instructional practice under differing circumstances. Adaptation involves the teacher or educational leader's ability to initiate modifications to the initial skill learned to applied it to another unique situation (e.g., different grade level or classroom, changes in the availability of resources) alone or as part of a team-based problem-solving and planning.

Understanding skill proficiency within this learning hierarchy informs the design of professional learning supports to advance targeted practices at each stage. For example, during the initial acquisition stage, instructional procedures should utilize demonstration, modeling, and cueing in combination with performance feedback (Haring \& Eaton, 1978). Practice is essential for skill development at the fluency stage, with research indicating that at least $70 \%$ of the allotted instructional time be devoted to skill practice (Binder, 1996). Building generalization involves structured opportunities to practice the skill over time, across a wide variety of possible settings and circumstances, and with the expectation that other related skills may also be strengthen (Stokes \& Baer, 1977). Adaptation requires skill proficiency and knowledge of the relevant content, contexts, and processes in order to identify the core elements of a practice and modify its use in response to novel settings and situations (Haring \& Eaton, 1978). Facilitating adaptation involves guidance and specific feedback regarding the type and degree of modifications permissible within the parameters of implementation fidelity. The Instructional Hierarchy model was shown to be relevant in identifying professional learning needs for technical assistance providers in a state-wide educational initiative (Morrison et al., 2014).

\subsection{Purpose of the Study}

Despite the need for quality professional learning to ensure teachers and educational leaders keep up with advances in the field, very little is known about their preferences for engaging in professional learning. This gap in the research literature is of particular concern as the pivot to fully remote learning throughout the COVID-19 pandemic gives way to post-pandemic planning for meeting teachers' professional development needs. The purpose of this study is to describe teacher and educational leaders' preferences for professional learning formats (i.e., face-to-face, remote, or hybrid) in 
relation to the session's learning objective as framed by the Instructional Hierarchy model. The study was designed to address the following research questions:

1. Does the preferred professional learning format vary by learning objective?

2. Which professional learning format is preferred for learning objectives that reflect a progression of professional practice skill development?

3. What is the preferred time of day and day of the week for professional learning delivered remotely?

This study extends the research literature by highlighting considerations that can be used to plan quality, cost effective professional learning experiences for teachers and educational leaders.

\section{Method}

\subsection{Respondents}

The respondents in this study included 236 educators and educational leaders in K-12 school systems in the state of Michigan located in the Midwestern United States. The respondents held a variety of roles that included general education teachers $(N=68)$, district administrators $(N=35)$, regional state support team staff $(N=35)$, school administrators $(N=27)$, special education teachers/interventionists $(N=23)$, related service providers $(N=21)$, and instructional coaches/consultants $(N=19)$, and other $(N=8)$. Respondents were asked to select one grade level band to best represented the students they served. The grade levels band selected by the respondents included K-5 $(N=93)$, K-12 $(N=84)$, Grades 6-8 $(N=23)$, Grades 9-12 $(N=21)$, Grades 6-12 $(N=9)$, and K-8 $(N=5)$. Just over half $(53 \%)$ of the respondents were affiliated with a school district or regional state support team that was participating in a professional learning series with Michigan's MTSS (MiMTSS) Technical Assistance Center. The majority had attending at least one professional learning sessions with the MiMTSS Technical Assistance Center during the previous school year (2020-2021), during which time, all professional learning series were delivered virtually in response to the public health emergency created by the COVID-19 pandemic.

\subsection{Procedures}

The MiMTSS Technical Assistance Center's Professional Learning Input Survey was designed collaboratively by professionals in the Center's Professional Learning Team and Evaluation and Research Team to better understand the needs and preferences of intended audience members. The survey was administered virtually from 8/1/2021 to 9/1/2021. A link to the survey was emailed via a listserv through the MiMTSS Technical Assistance Center Data System, which offers data warehousing, analysis, and reporting features for state educators.

\subsection{Instrument}

The survey instrument was comprised of 11 items. The first three items gathered background information on the respondent's professional role, grade levels supported, and current taught, professional role, and affiliation with a school district currently participating a professional learning series with MiMTSS Technical Assistance Center. A fourth survey item asked respondents to identify their preferred professional learning format (i.e., face-to-face, remote, hybrid) based on the learning objectives (e.g., learning a new skill, team-based problem solving and action planning) of the professional learning series. The remaining seven items asked respondents to provide their preferences (i.e., time of day, day of the week) and experiences (e.g., accessing a recording for an event attended, accessing materials for an event not attended).

\subsection{Data Analysis}

Descriptive statistics were used to summarize the survey data. Specifically, frequency counts and cross-tabulations were used to analyze survey responses.

\section{Results}

\subsection{Professional Learning Preference by Learning Objective}

The results of this study indicate that educators preferences for professional learning format varied by the intended learning objective of the session (see Figure 1). Professional learning using a face-to-face format was preferred relative to remote and hybrid options for a session in which the primary objective was to learn a new skill $(40 \%$ versus $25 \%$ and $16 \%$ ), practice new skills (39\% versus $23 \%$ and $17 \%$ ), and engage in team-based problem solving ( $41 \%$ versus $22 \%$ and $16 \%)$. Remote professional learning was preferred relative to face-to-face and hybrid formats for a session in which the primary objective was to share information uni-directionally from the presenter to the audience (53\% versus $25 \%$ and $22 \%$ preferred hybrid). The respondents were equally split in their preference for either a face-to-face or remote format when the learning objective was to understand new concepts and learn how to apply the concepts to their setting. There was no clear preference for a professional learning format that dominated across all types of learning objectives. 
Furthermore, within each type of learning objective the preferred format did not command a majority, with the exception of remote learning preferred by a slim majority (53\%) when the objective was informational.

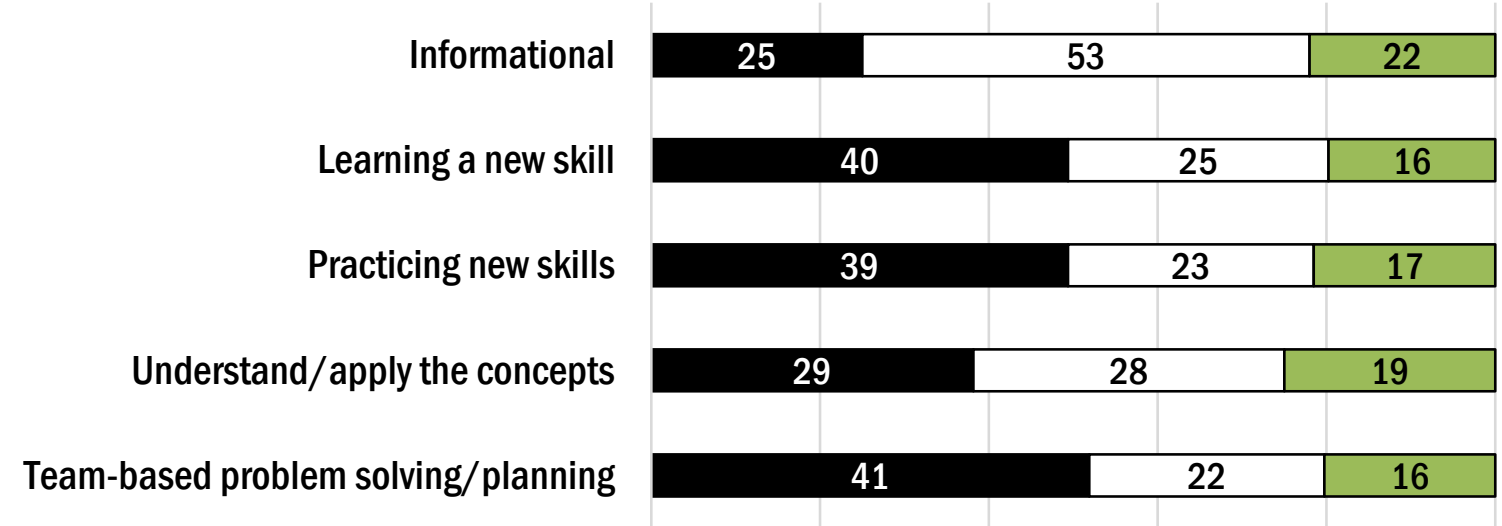

Percentage of Respondents

- Face-to-Face $\quad \square$ Remote $\quad \square$ Hybrid

Figure 1. Percentage of Respondents' Preferred Format for Professional Learning by Objective

\subsection{Professional Learning Preferences for Remote Delivery}

There was no overwhelming preference for a particular time of day for professional learning delivered remotely, although the majority of the respondents selected a time slot during school hours. Asked to select the time of day that works best for a 2-hour professional learning session presented remotely, "Before noon" was selected by 33\% of the respondents, followed by "Between noon and 3:00 pm" (28\%), "3:30 to 5:30 pm" (26\%), and "4:00 to 6:00 pm (13\%). An analysis by role indicates that teachers preferred afternoon time slots: "Between noon and 3:00 pm" (39\%), "3:30 to 5:30 pm" (36\%), "4:00 to 6:00 pm (18), and "Before noon" (8\%), whereas individuals in other educational leadership and support roles were divided equally in their preference for "Before noon" (29\%), "Between noon and 3:00 pm" $(30 \%)$, and "3:30 to $5: 30 \mathrm{pm}$ " $(28 \%)$ as displayed in Figure 2. For the preferred day of the week for professional learning, Wednesday was selected by $26 \%$ of the respondents, followed by Tuesday (24\%), Monday or Thursday $(15 \%$ each), Friday (13\%), Saturday (6\%), and Sunday (1\%).

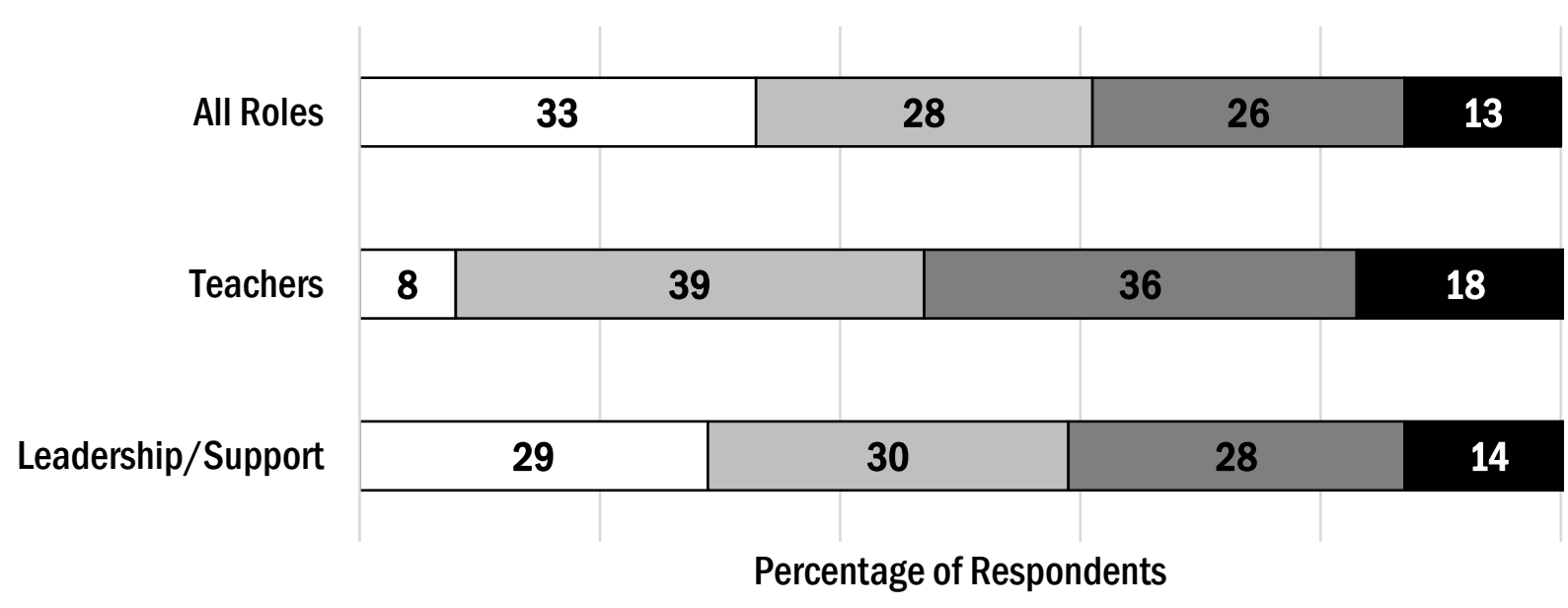

$\square$ Before noon $\square$ Between noon and 3:00 pm $\square 3: 30$ to $5: 30 \mathrm{pm} \quad \square$ 4:00 to 6:00 pm

Figure 2. Percentage of Respondents' Preferred Time of Day by Role 


\section{Discussion}

School shutdowns and other public health efforts to mitigate the deleterious impact of the COVID-19 pandemic forced communities to abruptly pivot to distance learning for students and remote work for educators. The heavy reliance on information technology and virtual platforms, born out of necessity during the pandemic, accelerated existing trends towards webinars, videos and other means of online professional development. As the public health crisis subsides, professionals in the field of education are seeking to design professional learning opportunities that are maximally effective, relevant, and useful for teachers and educational leaders. The purpose of this study was to better understand teacher and educational leaders' preferences for professional learning formats in relation to the intended learning objective.

The current study expands of previous survey research conducted since the start of the COVID-19 pandemic by focusing on the perspectives of teachers and educational leaders and by specifically accounting for the need to match preferred professional learning formats to a variety of learning objectives. Although there was no preferred professional learning format that dominated across all types of learning objectives, teachers and educational leaders did favor slightly one format over the others based upon the intended learning objective of the professional learning series. For example, remote learning preferred when the objective was informational whereas in-person sessions were preferred for when the objective was to learn a new skill, practice new skills, and engage in team-based problem solving. Importantly, within each type of learning objective the preferred format did not command a strong majority, suggesting that teachers and educational leaders collectively were not wedded to a single format for all of their professional learning.

The results of this study was consistent with previous research among students enrolled in university and community college classes in showing how preferences may differ by activity (i.e., face-to-face learning for discussions and for mastering more challenging content, remote online learning for independent pursuits, such as writing, and for less complex content). The current study differed from previous survey research conducting in the field of marketing that showed stronger preferences for in-person conferences. The preference for the day of the week (Wednesday, followed by Tuesday) was consistent with previous research in the field of marketing, as was the preference for time of day (morning) among educational leaders and educators in support roles. Teachers, however, preferred afternoon time slots, highlighting the importance of understanding preferences by professional role in educational settings.

\section{Limitations of the Study}

A primary limitation of this study was that relevant demographic information (i.e., age, region on the rural/urban continuum) was not gathered to enable further analysis of the teachers and educational leaders' preferences. Future research should examine preferences for professional learning formats by learning objective while taking into account the age and region on the rural/urban continuum of the individual respondent. Given that this study was conducted during a pandemic while public sentiment was running high with uncertainty, exhaustion, and loss, a follow-up study would provide valuable information on the degree to which teachers and educational leaders' preferences for professional learning have remained the same or changed over time.

A second limitation of the study was that the survey instrument was developed for the purposes of this inquiry and had not been rigorously validated prior to its use. A pilot study would have enabled the researchers to establish the technical adequacy of the instrument for its intended use in describing teacher and educational leaders' perceptions.

\section{Implications}

The major finding, that the selection of professional learning formats should consider the intended learning objective of the professional learning series, has important implications for designing professional learning. The development of a professional learning series should be driven by a needs assessment and designed in accordance with the Standards for Professional Learning (Learning Forward, 2012). Once the professional development needs are identified, the scope and sequence of the targeted content should be charted with clearly defined learning objectives marking each milestone. For each of the learning objectives, the professional learning session should be design to be maximally effective in ensuring the participants achieve that learning objective, whether it be through a face-to-face, remote, or hybrid format. In this study, no one format held a dominate position over the others in terms of educators' preferences. Capitalizing on technological innovations (e.g., breakout groups on virtual platforms, webcams placed in applied settings, bug-in-ear coaching and consultation) may enable a remote professional development experience that incorporates opportunities for the types of interactions traditionally available only through face-to-face sessions. 


\section{References}

Alexander, S. (2001). E-learning developments and experiences. Education and Training, 43, $240-248$. https://doi.org/10.1108/00400910110399247

Barnard, M., Whitt, E., \& McDonald, S. (2020). Learning objectives and their effects on learning and assessment preparation: Insights from an undergraduate psychology course. Assessment and Evaluation in Higher Education, 46(5), 673-684. https://doi.org/10.1080/02602938.2020.1822281

Bell, D. J., Self, M. M., Davis, C. Conway, F., Washburn, J. J., \& Crepeau-Hobson, F. (2020). Health service psychology education and training in the time of COVID-19: Challenges and opportunities. American Psychologist, 75(7), 919-932. https://doi.org/10.1037/amp0000673

Besser, A., Flett, G. L., \& Zeigler-Hill, V. (2020). Adaptability to a sudden transition to online learning during the COVID-19 pandemic: Understanding the challenges for students. Scholarship of Teaching and Learning in Psychology. https://doi.org/10.1037/st10000198

Binder, C. (1996). Behavioral fluency: Evolution of a new paradigm. The Behavior Analyst, 19(2), $163-197$. https://doi.org/10.1007/BF03393163

Chen, P. S., Lambert, A. D., \& Guidry, K. R. (2010). Engaging online learners: the impact of web-based learning technology on college student engagement. Computers and Education, 54, 1222-1232. https://doi.org/10.1016/j.compedu.2009.11.008

Conole, G., de Laat, M., Dillon, T., \& Darby, J. (2008). "Disruptive technologies”, “pedagogical innovation": what's new? Findings from an in-depth study of students' use and perception of technology. Computers and Education, 50, 511-524. https://doi.org/10.1016/j.compedu.2007.09.009

Dias, M. O., Lopes, R. O. A., \& Teles, A. C. (2020). Will virtual replace classroom teaching? Lessons from virtual classes via Zoom in the times of COVID-19. Journal of Advances in Education and Philosophy, 4(5), $208-213$. https://doi.org/10.36348/jaep.2020.v04i05.004

Dvořáková, K., Emmer, J., Janktová, R., \& Klementová, K. (2021). From F2F to ERT: University students’ perception of remote learning during the first COVID-19 lockdown. Journal on Efficiency and Responsibility in Education and Science, 14(2), 89-100. https://doi.org/10.7160/eriesj.2021.140203

EdWeek Research Center. (2021). What School and District Leaders Get, Want, and Need from Professional Development [Special Report]. EdWeek. https:/www.edweek.org/leadership/what-school-and-district-leaders-get-want-and-need-from-professional-develop ment $/ 2021 / 11$

Fichten, C., Havel, A., Wileman, S., Jorgensen, M., Arcuri, R., \& Ruffolo, O. (2021). Digital tools faculty expected students to use during the COVID-19 pandemic in 2021: Problems and solutions for future hybrid and blended courses. Journal of Education and Training Studies, 9(8), 24-30. https://doi.org/10.11114/jets.v9i8.5310

Haring, N. G., \& Eaton, M. D. (1978). Systematic procedures: An instructional hierarchy. In N. G. Haring, T. C. Lovitt, M. D., Eaton, \& C. L. Hansen (Eds.), The fourth R: Research in the classroom. Charles E. Merrill Publishing Company.

Ituma, A. (2011). An evaluation of students' perceptions and engagement with e-learning components in a campus based university. Active Learning in Higher Education, 12, 57-68. https://doi.org/10.1177/1469787410387722

Jaggars, S. S. (2014). Choosing between online and face-to-face courses: Community college student voices. American Journal of Distance Education, 28, 27-38. https://doi.org/10.1080/08923647.2014.867697.

Kemp, N., \& Grieve, R. (2014). Face-to-face or face-to-screen? Undergraduates' opinions and test performance in classroom vs. online learning. Frontiers in Psychology, 12. https://doi.org/10.3389/fpsyg.2014.01278.

Learning Forward. (2012). Standards for $\quad$ Professional Learning. http://learningforward.org/standards-for-professional-learning

Markletic. (2021). Preferences towards In-Person versus Virtual Version of Hybrid Events Among Business-to-Business Marketers Worldwide as of February 2021. https://www.statista.com/statistics/1266059/version-hybrid-events/

Morrison, J. Q., Russell, C., Dyer, S., Metcalf, T., \& Rahschulte, R. (2014). Organizational structures and processes to support and sustain effective technical assistance in a state-wide multi-tiered system of support initiative. Journal of Education and Training Studies, 2(3), 129-137.

Otter, R. R., Seipel, S., Graeff, T., Alexander, B., Boraiko, C., Gray, J., Sadler, K., et al. (2013). Comparing student and faculty perceptions of online and traditional courses. The Internet and Higher Education, 19, $27-35$. 
https://doi.org/10.1016/j.iheduc.2013.08.001

PromoLeaf. (2020). The Surprising Truth about Virtual vs. In-Person Conferences. [Blog posted on 5/1/2020]. https://promoleaf.com/blog/the-surprising-truth-about-virtual-vs-in-person-conferences

Robinson, C. C., \& Hullinger, H. (2008). New benchmarks in higher education: Student engagement in online learning. The Journal of Education for Business, 84, 101-109. https://doi.org/10.3200/JOEB.84.2.101-109

Schoepp, K. (2017). The state of course learning outcomes at leading universities. Studies in Higher Education, 44(4), 615-627. https://doi.org/10.1080/03075079.2017.1392500

Stokes, T. F., \& Baer, D. M. (1977). An implicit technology of generalization. Journals of Applied Behavior Analysis, 10(2), 349-367. https://doi.org/10.1901/jaba.1977.10-349

Sun, M., Loeb, S., \& Grissom, J. A. (2017). Building teacher teams: Evidence of positive spillovers from more effective colleagues. Educational Evaluation and Policy Analysis, 39, 104-125. https://doi.org/10.3102/0162373716665698

Sun, M., Penuel, W. R., Frank, K. A., Gallagher, H. A., \& Youngs, P. (2013). Shaping professional development to promote the diffusion of instructional expertise among teachers. Educational Evaluation and Policy Analysis, 35(3), 344-369. https://doi.org/10.3102/0162373713482763

Upton, D. (2006). Online learning in speech and language therapy: student performance and attitudes. Education for Health, 19, 22-31. https://doi.org/10.1080/13576280500534735

WestEd. (2021, August 19). What can the scramble to get classrooms online during COVID teach us about better professional learning? $\quad$ [Blog $\quad$ post]. WestEd. https://www.wested.org/wested-insights/covid-lessons-about-professional-learning

Zhang, W. Y., \& Perris, K. (2004). Researching the efficacy of online learning: A collaborative effort amongst scholars in Asian open universities. Open Learning: The Journal of Open, Distance and e-Learning. 19, 247-264. https://doi.org/10.1080/0268051042000280110

\section{Copyrights}

Copyright for this article is retained by the author(s), with first publication rights granted to the journal.

This is an open-access article distributed under the terms and conditions of the Creative Commons Attribution license which permits unrestricted use, distribution, and reproduction in any medium, provided the original work is properly cited. 